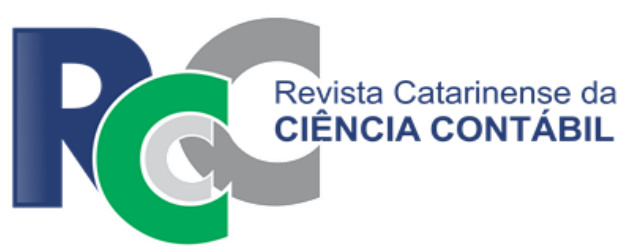

\title{
HÁ VAGAS: ANÁLISE DO PERFIL PROFISSIONAL REQUERIDO PELO MERCADO DE TRABALHO PARA PROFISSIONAIS CONTÁBEIS DA ÁREA DE CUSTOS
}

\author{
THERE ARE VACANCIES: ANALYSIS OF THE PROFESSIONAL PROFILE \\ REQUIRED BY THE LABOR MARKET FOR ACCOUNTING PROFESSIONALS \\ IN THE COST AREA
}

\author{
ALISON MARTINS MEURER \\ Universidade Federal do Paraná. Endereço: Av. Prefeito Lothário Meissner, \\ 668-794 | Jardim Botânico | 82590-300| Curitiba/PR | Brasil. \\ (D) http://orcid.org/0000-0002-3704-933X \\ alisonmmeurer@gmail.com
}

\section{SIMONE BERNARDES VOESE}

Universidade Federal do Paraná. Endereço: Av. Prefeito Lothário Meissner, 668-794 | Jardim Botânico | 82590-300| Curitiba/PR | Brasil.

Dhttp://orcid.org/0000-0002-5555-8250

simone.voese@ufpr.br

\begin{abstract}
RESUMO
O estudo teve como objetivo analisar o perfil requerido pelo mercado de trabalho para profissionais contábeis da área de custos a partir das diretrizes da International Federation of Accountants (IFAC), sendo analisadas 155 vagas de emprego anunciadas no site Manager Empregos. As redes de coocorrência obtidas pelo coeficiente de Jaccard permitiram delinear o perfil profissional requerido pelo mercado de trabalho. Os achados indicam que possuir conhecimentos multidisciplinares, elaborar relatórios para tomada de decisão, dominar elementos da tecnologia da informação e da língua inglesa estão entre os anseios técnicos identificados. Em relação às professional skills, foi verificado que ter habilidades de comunicação, pensamento crítico e analítico, visão sistêmica, foco, organização e ética são características destacadas pelas organizações que pretendem contratar profissionais de custos. Os resultados implicam a importância de desenvolver, além de competências técnicas, também habilidades sociais com os discentes dos cursos de Ciências Contábeis para que sejam supridas as demandas do mercado de trabalho e para que os estudantes consigam tornar seus currículos atrativos para as organizações e superar barreiras por vezes existentes devido à pouca experiência profissional no mercado de trabalho.
\end{abstract}

Palavras-chave: Perfil Profissional. Professional Skills. Technical Competencies. 


\begin{abstract}
This study aimed to analyze the profile required by the labor market for accounting professionals in the area of costs, based on the guidelines of the International Federation of Accountants (IFAC), analyzing 155 job openings announced on the Manager Jobs website. The co-occurrence networks obtained by the Jaccard coefficient allowed for outlining the professional profile required by the job market. The findings indicate that, showing multidisciplinary knowledge, preparing reports for decision making, mastering elements of information technology and English language are among the identified technical concerns. Regarding professional skills, we found that possessing communication skills, critical and analytical thinking, systemic vision, focus, organization and ethics are highlighted by organizations that intend to hire cost professionals. The results imply the importance of developing, besides technical skills, social skills with students of Accounting courses in order to meet the demands of the labor market, and for students to become able to make their curricula attractive to organizations and overcome barriers sometimes existing due to little professional experience in the job market.
\end{abstract}

Keywords: Professional Profile. Professionals Skills. Technical Competencies.

\title{
1 INTRODUÇÃO
}

É plausível afirmar que o vasto número de estudos internacionais desenvolvidos ao longo do tempo permitiu mapear as habilidades técnicas (hard skills) e comportamentais (soft skills) requeridas ao profissional contábil atuante na área de custos. Crossman (1953), Loft (1986) e Johnson e Johnson (1995) são exemplos de trabalhos desenvolvidos em diversas épocas com essa finalidade. Entretanto, no contexto nacional essa temática ainda é incipiente, e as investigações têm sido direcionadas para as hard skills (e.g. Souza \& Gomes, 2013; Anzilago, Bernd \& Voese, 2016).

Incentivada por esta configuração de pesquisa empírica-teórica disponível, esta investigação pretende abordar, além das hard skills, uma temática igualmente relevante: as soft skills. Conceituadas como habilidades comportamentais (Herawati, 2012), as soft skills têm conquistado espaço na formação do profissional contábil e são tratadas pela International Federation of Accountants (IFAC) como o conjunto de professional skills essenciais à formação desses profissionais. A IFAC também aborda as hard skills a partir das technical competencies (IFAC, 2014a, 2014b). As diretrizes da IFAC direcionam este estudo, que visa analisar o perfil requerido pelo mercado de trabalho para profissionais contábeis da área de custos, sendo justificado sob quatro argumentos.

Primeiro, o ambiente em que os contadores trabalham está mudando rapidamente, exteriorizando novos desafios para esses profissionais (Holtz, Cabral \& Carvalho, 2019). Preobragenskaya e Komarev (2018) e Tan e Laswad (2018) sugerem que os programas pedagógicos dos cursos de Ciências Contábeis não estão em harmonia com as necessidades dos empregadores, fato que aumenta as pressões sobre as universidades devido ao descontentamento dos contratantes com a formação dos graduados recrutados.

Segundo, importantes veículos de comunicação têm destacado que profissionais da área de custos estão entre os mais desejados pelas organizações (G1, 2013; Forbes, 2016), com salários em alta (Forbes, 2016; Michel Page, 2019) e área de atuação em expansão (Exame, 2016). Além das competências técnicas, têm sido exigidas desses profissionais habilidades comportamentais que englobam desde proatividade até a facilidade em estabelecer bons relacionamentos interpessoais (G1, 2013; Exame, 2016). É importante que os acadêmicos de Contabilidade estejam cientes destas demandas do mercado de trabalho e busquem desenvolver essas habilidades para que possam aumentar suas chances de empregabilidade e contribuir com a maximização do valor das organizações (Tan \& Laswad, 2018). 
Terceiro, a IFAC (2014a, 2014b) alerta que nem todas as technical competencies e professional skills são passíveis de serem desenvolvidas durante a formação universitária dos estudantes, sendo importante que os acadêmicos busquem também desenvolver essas competências e habilidades fora dos muros das universidades. Contudo, os órgãos membros da IFAC têm a responsabilidade de direcionar esforços para que esses requisitos sejam desenvolvidos no âmbito acadêmico. Em relação ao Brasil, Lemes e Miranda (2014) alertam que as normas do Conselho Federal de Contabilidade (CFC) que pautam as propostas para elaboração dos currículos dos cursos de Ciências Contábeis não estão alinhadas às diretrizes da IFAC, fomentando dúvidas sobre a harmonia dessas normas brasileiras diante das demandas do mercado de trabalho e das recomendações internacionais.

Por fim, o quarto argumento pauta-se na necessidade de constante interação entre a academia e o mercado de trabalho. Holtz et al. (2019) identificaram que as instituições de ensino superior não aderiram às technical competencies e às professional skills da IFAC em seus projetos pedagógicos de curso (PPC). Por meio dos resultados desta investigação, pretende-se reforçar a relevância do alinhamento entre as instituições de ensino superior, os entes governamentais e os órgãos de classe no intuito de adotar as diretrizes da IFAC na formação dos profissionais contábeis, em especial da área de custos, a fim de atualizá-los com as demandas de empregadores.

A partir de anúncios de empregos para profissionais contábeis na área de custos, busca-se responder à seguinte questão de pesquisa: qual o perfil profissional requerido pelo mercado de trabalho para profissionais contábeis da área de custos?

\section{TECHNICAL COMPETENCIES E PROFESSIONAL SKILLS}

O International Accounting Education Standards Board (IAESB) é o órgão vinculado à IFAC que tem entre suas atribuições o desenvolvimento de padrões educacionais e orientações para a qualificação e o desenvolvimento continuado dos profissionais contábeis. O IAESB foi responsável por emitir a International Education Standard (IES) 3, que trata das professional skills a serem desenvolvidas por acadêmicos em formação. Essas habilidades devem ser fomentadas durante o processo inicial de formação dos contadores juntamente com as technical competencies (IES 2), valores, ética e atitudes profissionais (IES 4) (IFAC, 2014a, 2014b, 2014c).

As professional skills são categorizadas pela IFAC como as de caráter (a) intelectual, (b) interpessoal e de comunicação, (c) pessoal e (d) organizacional. As habilidades intelectuais tratam da capacidade do contador de exercer julgamento profissional e resolver problemas relacionados às práticas de trabalho. Em termos de relacionamento interpessoal e comunicação, a IES 3 direciona olhares para a aptidão em estabelecer relacionamentos e interagir com terceiros. No âmbito pessoal busca-se desenvolver habilidades direcionadas para atitudes e comportamentos dos futuros contadores, como visão crítica e ceticismo; enquanto no aspecto organizacional almeja-se desenvolver habilidades para que o contador consiga desenvolver suas atividades no ambiente empresarial, obtendo resultados satisfatórios com os recursos disponíveis. O foco dessa IES está na capacidade de liderança para atingir os objetivos propostos e no uso adequado da tecnologia (IFAC, 2014b).

Por sua vez, a IES 2 trata das technical competencies, que também devem ser desenvolvidas por contadores em formação. Essas competências envolvem conhecimentos relacionados a contabilidade financeira e seus relatórios, contabilidade gerencial, finanças e gestão financeira, tributação, auditoria e garantia, governança, gerenciamento de riscos e controle interno, direito e legislação comercial, tecnologia da informação, ambiente empresarial e organizacional, e economia. As technical competencies estabelecem as bases para a realização das atividades dos contadores profissionais. As competências destacadas no âmbito da contabilidade gerencial abordam diretamente competências ensejadas para os profissionais da área de custos, tais como: apoiar as decisões gerenciais, por meio do cálculo de custos, análise de variação, gerenciar estoque, realizar orçamentos e previsões, definir direcionadores de custos, analisar dados financeiros e não 
financeiros, e desenvolver relatórios capazes de apoiar as decisões nos âmbitos de planejamento, gerenciamento, controle de qualidade e benchmarking (IFAC, 2014a).

$\mathrm{Na}$ literatura nota-se o crescente número de pesquisas que direcionam atenção para os diferentes tipos de competências técnicas e habilidades sociais dos profissionais contábeis, das quais é possível citar: Maelah, Aman, Mohamed e Ramli (2012); Lemes e Miranda (2014); Anzilago et al. (2016); Tan e Laswad (2018); Heang, Mee, Ramalingam e Hoe (2019); e Holtz et al. (2019).

Maelah et al. (2012) verificaram as habilidades desenvolvidas por estudantes de bacharelado em Ciências Contábeis da Malásia ao participar de programas de trainee em indústrias. Os achados indicaram que a gestão do tempo, a comunicação oral e a capacidade de trabalhar em grupo estão entre as habilidades desenvolvidas durante essa imersão no mercado de trabalho. Os resultados ainda revelam a importância de inserir os discentes no mercado de trabalho durante o período da graduação para que sejam desenvolvidas e lapidadas habilidades exigidas no ambiente profissional, que em alguns casos não são totalmente observadas durante a formação universitária.

Tan e Laswad (2018) analisaram as habilidades requeridas dos profissionais contábeis em anúncios de emprego divulgados na Austrália e na Nova Zelândia. Foi verificado que as habilidades interpessoais são requeridas com maior frequência do que as técnicas. As soft skills mais citadas nos anúncios tratam da colaboração com os colegas de trabalho. Além da capacidade de apresentar, discutir e defender pontos de vista (comunicação, apresentação e habilidades de fala), atitude positiva - ser comprometido, apaixonado, dinâmico, enérgico e vibrante -, uso da tecnologia da informação, habilidades de liderança, cumprir os prazos estabelecidos, entender dinâmicas de grupo, atenção e consciência de suas funções, agir estrategicamente, pensar e agir independentemente, analisar, raciocinar e conceituar questões, ser flexível, resolver problemas e construir argumentos estão entre as características mais valorizadas pelos empregadores.

Sob a mesma ótica, Heang et al. (2019) analisaram as principais habilidades listadas em anúncios de empregos para graduados na área de negócios da Malásia. A área de negócios englobou vagas para Contabilidade/Finanças, Administração/Recursos Humanos e Vendas/Marketing. Especificamente em Contabilidade/Finanças foram identificados 5.122 anúncios, dos quais 100 foram verificados detalhadamente. As cinco habilidades com maior frequência foram: apresentar, discutir e defender pontos de vista, domínio da tecnologia da informação, fluência em inglês, pensar e agir de forma independente, e ter boa comunicação. Essas habilidades apresentam-se como essenciais para o desenvolvimento das atividades dos profissionais atuantes nas diferentes facetas da Contabilidade, pois é exigida durante o processo decisório a aplicação de aptidões profissionais plurais, que transcendem as competências técnicas do escopo de atuação profissional.

No Brasil, Lemes e Miranda (2014) investigaram o grau de importância que profissionais de Contabilidade atribuem às habilidades expostas na IES 3. Todas as habilidades preconizadas pela IES 3 apresentaram elevado grau de importância, com destaque para: capacidade de trabalhar em equipe, iniciativa, influência e autoaprendizagem, e observar as implicações de valores, ética e atitudes nas tomadas de decisões. As críticas recaem sobre o fato de as diretrizes do CFC não englobarem as professional skills apresentadas na IES 3. Como consequência, os PPCs de Ciências Contábeis não englobam tais habilidades, fato identificado por Holtz et al. (2019) ao analisar os PPCs das instituições de ensino superior federais que ofertam o curso de Ciências Contábeis.

Anzilago et al. (2016) realizaram um estudo descritivo sobre os conhecimentos e as competências técnicas exigidas de profissionais de custos no estado do Paraná. Foram identificadas 92 vagas de emprego anunciadas em plataformas on-line. Os achados apontaram que a formação em Ciências Contábeis, o domínio da língua inglesa e de ferramentas como Excel e Pacote Office, conhecimentos de gestão de custos e orçamentos, experiência em custos, elaboração de relatórios contábeis e gerenciais, e domínio de métodos de custeio de produtos figuram entre os principais anseios do mercado de trabalho. Os achados denotam a importância de o profissional 
da área de custos manter-se atualizado com as demandas do mercado de trabalho e de estar engajado em processos de capacitação técnica contínua.

Além de Lemes e Miranda (2014), Anzilago et al. (2016) e Holtz et al. (2019), outras pesquisas (e.g. Reis, Sediyama, Moreira \& Moreira, 2015) desenvolvidas no contexto brasileiro discutiram as competências e habilidades dos profissionais da área contábil. Juntamente com os conhecimentos técnicos, os acadêmicos devem desenvolver habilidades sociais, na medida em que dispor de competências estritamente técnicas pode não se converter em elementos competitivos no mercado de trabalho (Heang et al., 2019). Assim, este artigo busca contribuir com os achados anteriores ao analisar especificamente as habilidades demandadas pelo mercado de trabalho para profissionais contábeis atuantes na área de custos, visto que as funções vinculadas a essa faceta da Contabilidade estão entre as mais desejadas e em expansão no Brasil (G1, 2013; Exame, 2016; Forbes, 2016).

\section{METODOLOGIA}

Os dados foram coletados a partir de anúncios de vagas de emprego para profissionais da área de custos divulgados no site Manager Empregos (manager.com.br), que foram coletados diariamente entre $1^{\circ}$ de abril de 2019 e $1^{\circ}$ de julho de 2019, sendo cada vaga identificada por um código (ID). A opção pelo Manager Empregos deu-se por dois motivos. Primeiro, pelo fato de o site ser "especializado em vagas nas carreiras gerenciais, com foco em Administração, Indústria, Área Comercial, Logística e Atendimento" (Guia da Carreira, 2019). Segundo, porque, dentre os maiores sites de anúncios de vagas de emprego, o Manager é o que possui maior detalhamento dos requisitos desejados pelos contratantes.

Os filtros que caracterizaram a busca foram a presença da palavra "Custos" no título da vaga, a formação em "Ciências Contábeis" ou a área de atuação ser "Contabilidade". A análise foi delimitada às vagas anunciadas no estado de São Paulo, em função de este estado possuir 26,1\% do número de estabelecimentos industriais do Brasil, representar 30,4\% de participação na força de trabalho industrial do país (Confederação Nacional das Indústrias [CNI], 2017), setor que aglomera a maior parte dos profissionais da área de custos, e contribuir com mais de $30 \%$ do PIB nacional (Instituto Brasileiro de Geografia e Estatística [IBGE], 2016). Assim, foram identificadas 155 vagas alinhadas aos critérios de busca da pesquisa.

Os dados de cada vaga ofertada foram tabulados em planilha eletrônica e analisados por meio de estatística descritiva e formação de redes de coocorrências com auxílio do software KH Coder $3 \circledR$. A rede de coocorrência permite que diagramas de rede sejam desenhados a fim de mostrar as palavras com padrões de aparecimento semelhantes, com altos graus de coocorrência e conectadas por linhas. Esses diagramas identificam grupos, que são denominados de comunidades, e agrupam as palavras de acordo com sua aproximação, sendo indicadas as similaridades. As relações existentes entre as palavras das redes são obtidas pelo coeficiente de Jaccard, que varia de 0 a 1 - quanto mais próximo de 1 , maior é a similaridade entre as descrições analisadas. Assim, o coeficiente de Jaccard "enfatiza se palavras específicas coocorrem ou não. Isso é válido, independentemente de a palavra aparecer uma ou dez vezes em um documento. Assim, a palavra de coocorrência é calculada independentemente da frequência de apresentação" (Higuchi, 2017, p. 50). Entre as vantagens do uso da rede de coocorrência está a minimização dos riscos advindos da subjetividade do pesquisador, na medida em que as evidências são obtidas de forma objetiva. Esta pesquisa busca, por meio do coeficiente de Jaccard, identificar similaridades nos anúncios das vagas de emprego, permitindo o delineamento do perfil almejado pelo mercado de trabalho. 


\section{ANÁLISE E DISCUSSÃO DOS RESULTADOS}

Na Tabela 1 são elencadas algumas informações acerca das vagas analisadas.

Tabela 1

\section{Características das vagas analisadas}

\begin{tabular}{|c|c|c|c|}
\hline \multicolumn{4}{|c|}{ Porte } \\
\hline Microempresa - até 19 funcionários & 31 & Média - entre 100 e 499 funcionários & 61 \\
\hline Pequena - entre 20 e 99 funcionários & 31 & Grande - acima de 500 funcionários & 32 \\
\hline \multicolumn{2}{|l|}{ Cargo } & \multicolumn{2}{|l|}{$\begin{array}{l}\text { Faixa salarial }(\mathrm{R} \$) \\
\end{array}$} \\
\hline Analista & 121 & De 1.001 até 2.000 & 16 \\
\hline Assistente & 17 & De 2.001 até 3.000 & 10 \\
\hline Auxiliar & 4 & De 3.001 até 4.000 & 24 \\
\hline Estagiário & 4 & De 4.001 até 5.000 & 14 \\
\hline Supervisor/coordenador & 7 & De 5.001 até 6.000 & 11 \\
\hline Outros & 2 & Acima de 6.000 & 4 \\
\hline & & A combinar & 76 \\
\hline
\end{tabular}

Fonte: Elaborada pelos autores.

A maioria dos anúncios foi realizada por empresas de médio porte, que possuem entre 100 e 499 funcionários. Assim como encontrado por Anzilago et al. (2016), o cargo mais anunciado foi o de analista de custos, englobando os níveis júnior, pleno e sênior. Em 76 vagas não houve detalhamento da remuneração, e em 24 anúncios a faixa salarial estava entre $R \$ 3.001$ e $R$ \$ 4.000. $\mathrm{Na}$ Tabela 2 são mostrados alguns requisitos prévios listados nas vagas.

Tabela 2

\section{Requisitos prévios exigidos}

\begin{tabular}{|c|c|c|c|}
\hline \multicolumn{2}{|c|}{ Experiência anterior } & \multirow{2}{*}{\multicolumn{2}{|c|}{ Conhecimento prévio* }} \\
\hline \multirow{2}{*}{$\begin{array}{l}\text { Experiência na área } \\
\text { Não requer/não cita experiência }\end{array}$} & \multirow{2}{*}{$\begin{array}{c}107 \\
48\end{array}$} & & \\
\hline & & Excel & 16 \\
\hline \multicolumn{2}{|c|}{ Idioma } & Protheus & 9 \\
\hline Inglês avançado & 8 & SAP & 10 \\
\hline Inglês intermediário & 11 & Pacote Office & 4 \\
\hline Não requisitado & 136 & Outros/não requisitado & 121 \\
\hline
\end{tabular}

Nota. * Uma mesma vaga pode possuir mais de um requisito de conhecimento prévio.

Fonte: Elaborada pelos autores.

Em 107 vagas há exigência de experiência anterior na área de custos; e em 19 anúncios foi exigido o domínio da língua inglesa, seja no nível intermediário ou avançado. Em termos percentuais, Anzilago et al. (2016) encontraram maior número de vagas que exigiam domínio da língua estrangeira. Por fim, quanto ao conhecimento prévio, nota-se ênfase no domínio e uso de alguns softwares utilizados na rotina dos profissionais de custos, tais como Excel, softwares que compõem o Pacote Office e de enterprise resource planning (ERPs) robustos, como Protheus e SAP. Logo, o domínio do idioma inglês e a experiência com o uso de ERPs gerenciais são aspectos que podem servir como diferenciais para os candidatos que almejam conquistar vagas disponíveis para profissionais contábeis na área de custos.

A fim de identificar as similaridades entre funções, porte da empresa, salário e os requisitos prévios, foi construída a rede de coocorrência mostrada na Figura 1. 


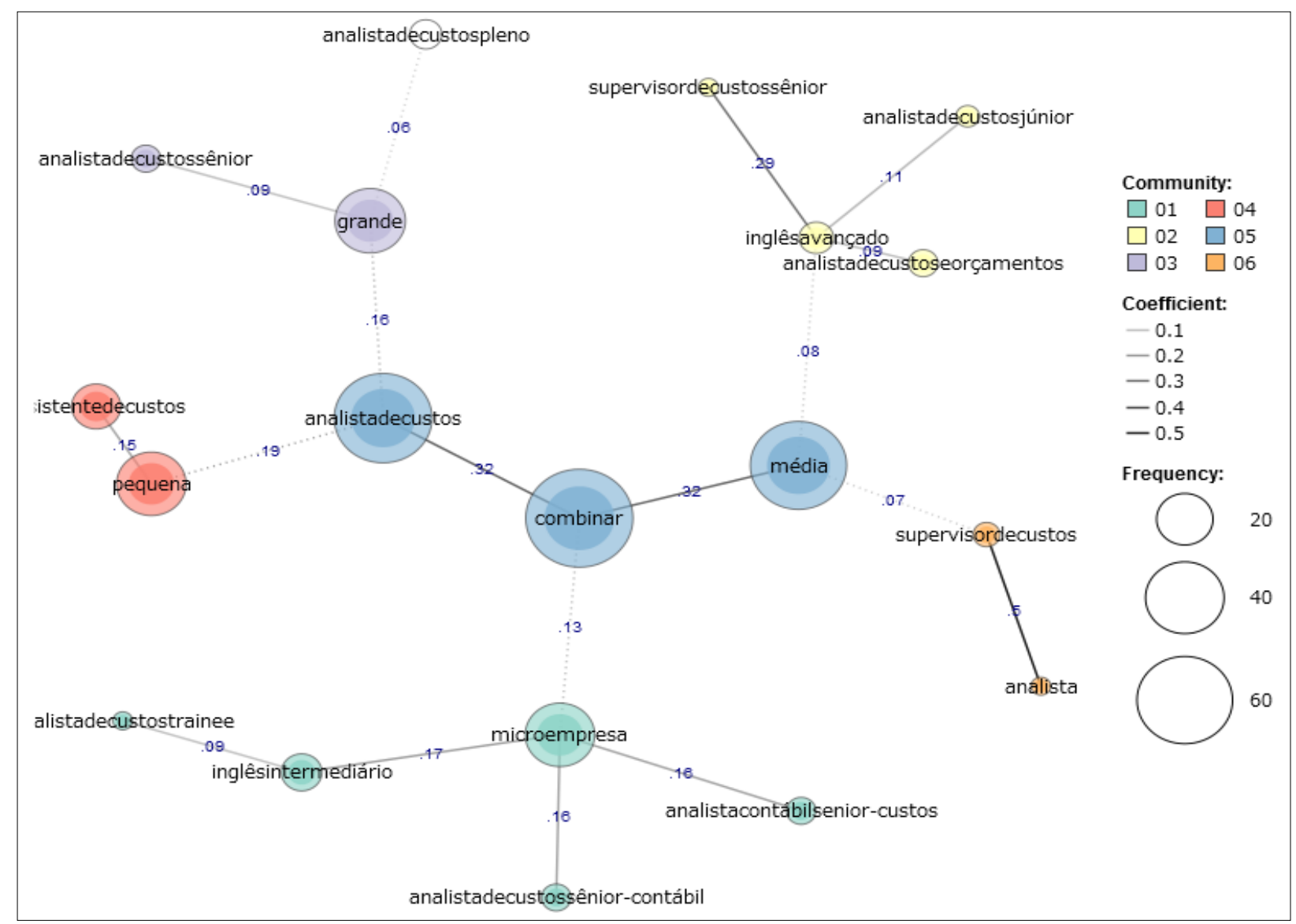

Figura 1. Rede de coocorrência entre funções, porte da empresa, salário e requisitos prévios Fonte: Elaborada pelos autores.

Nota-se que, na comunidade 1 , as vagas que exigem inglês intermediário estão associadas ao analista de custos trainee $(\mathrm{J}=0,09)$, e com maior intensidade às microempresas $(\mathrm{J}=0,17)$. A formação da comunidade 2 indica que há maior associação do nível de inglês avançado com vagas para supervisor de custos sênior $(J=0,29)$, analista de custos júnior $(J=0,11)$ e analista de custos e orçamentos $(\mathrm{J}=0,09)$. Na comunidade 3 , as vagas de analista de custos sênior têm maior associação com empresas de grande porte. Por sua vez, na comunidade 4 é percebido que os assistentes de custos estão relacionados com empresas de pequeno porte $(\mathrm{J}=0,15)$. Na comunidade 5, as vagas que possuem salário a combinar estão mais associadas às empresas de médio porte $(\mathrm{J}=0,32)$ e à função de analista de custos $(\mathrm{J}=0,32)$. Por fim, a comunidade 6 aponta similaridade entre os requisitos das vagas de supervisor de custos e analista $(\mathrm{J}=0,50)$.

Com objetivo de identificar as technical competencies e funções que são exercidas pelos profissionais de custos, a partir do detalhamento das vagas foi construída a rede de coocorrência exposta na Figura 2. 


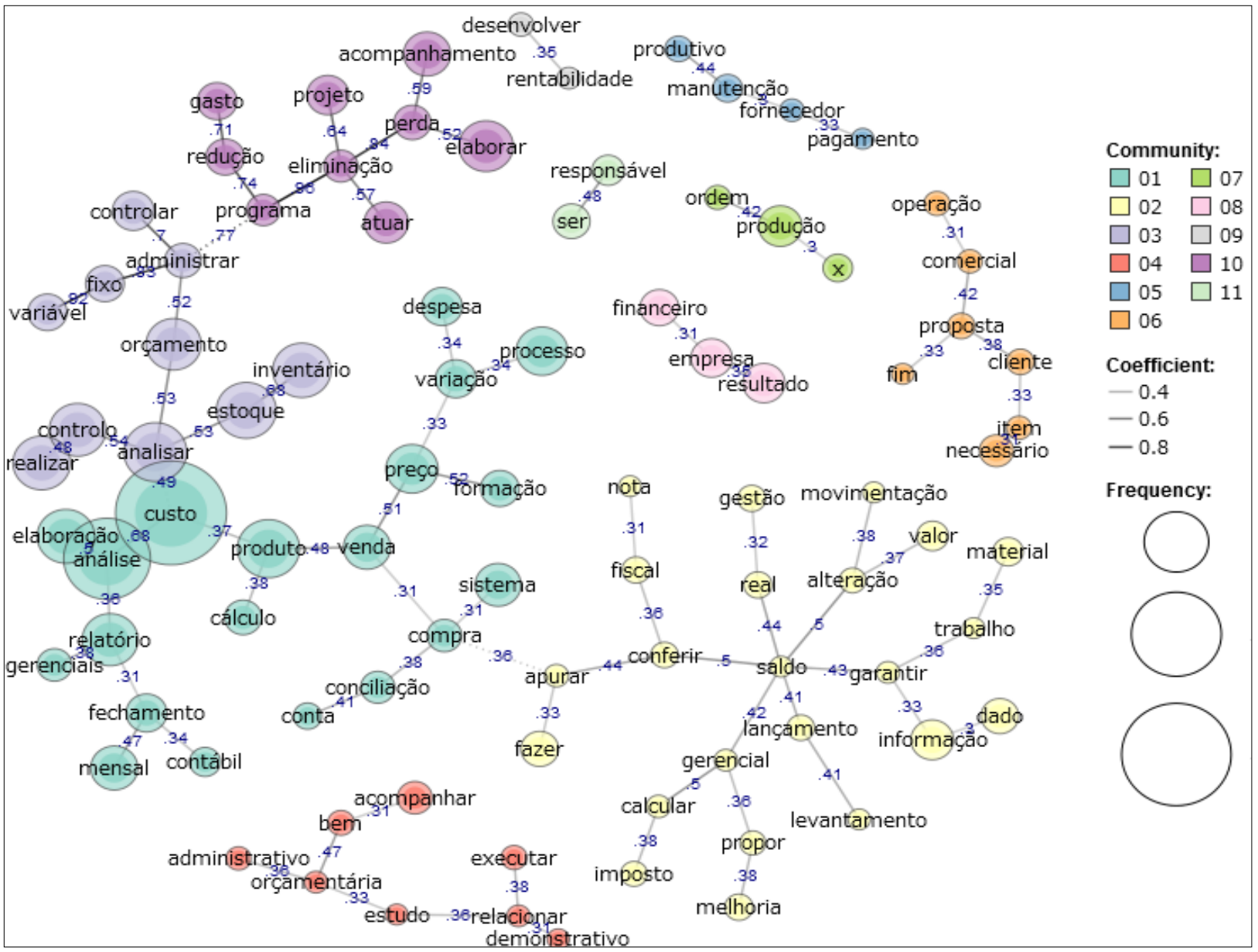

Figura 2. Rede de coocorrência de competências técnicas e funções a serem desempenhadas Fonte: Elaborada pelos autores.

A comunidade 2 indica associações com aspectos tributários, uma vez que são aglutinadas palavras como "fiscal", "nota", "imposto" e "apuração". Na comunidade 3, por sua vez, há associações entre as palavras "fixo" e "variável" $(\mathrm{J}=0,92)$, "estoque" e "inventário" $(\mathrm{J}=0,68)$, e "controlar" e "administrar" $(\mathrm{J}=0,70)$. Entre os relacionamentos expostos na comunidade 4, houve associação da palavra "orçamentária" com "administrativo" $(\mathrm{J}=0,36)$ e "estudo" $(\mathrm{J}=0,33)$, indicando que entre as atividades exercidas pelo profissional de custos está o acompanhamento dos resultados alcançados pela organização.

As tarefas inerentes ao relacionamento com fornecedores, tais como pagamento, foram aglutinadas na comunidade 5, enquanto relacionamento com clientes, atividades comerciais e desenvolvimento de propostas foram elencados na comunidade 6. Por sua vez, a comunidade 7 apresentou palavras relacionadas à produção, e a comunidade 8 ao setor financeiro. $\mathrm{Na}$ comunidade 9 houve associação entre as palavras "desenvolver" e "rentabilidade" $(\mathbf{J}=0,35)$, indicando que entre as funções do profissional de custos está o desenvolvimento de relatórios que permitem acompanhar a rentabilidade da organização.

Na comunidade 10 foram associadas palavras que remetem à eficiência da entidade, sendo associada a palavra "redução" com "programa" $(\mathrm{J}=0,74)$ e "gastos" $(\mathrm{J}=0,71)$, e "eliminação" com "programa" $(\mathrm{J}=0,96)$ e "perda" $(\mathrm{J}=0,94)$. Por fim, a comunidade 11 apontou associação entre as palavras "ser" e "responsável" $(\mathrm{J}=0,48)$, ocasionada pela diversidade de funções que ficam sob a responsabilidade do profissional de custos.

A Figura 3 apresenta a rede de coocorrência formada a partir das professional skills identificadas nas vagas de emprego analisadas. 


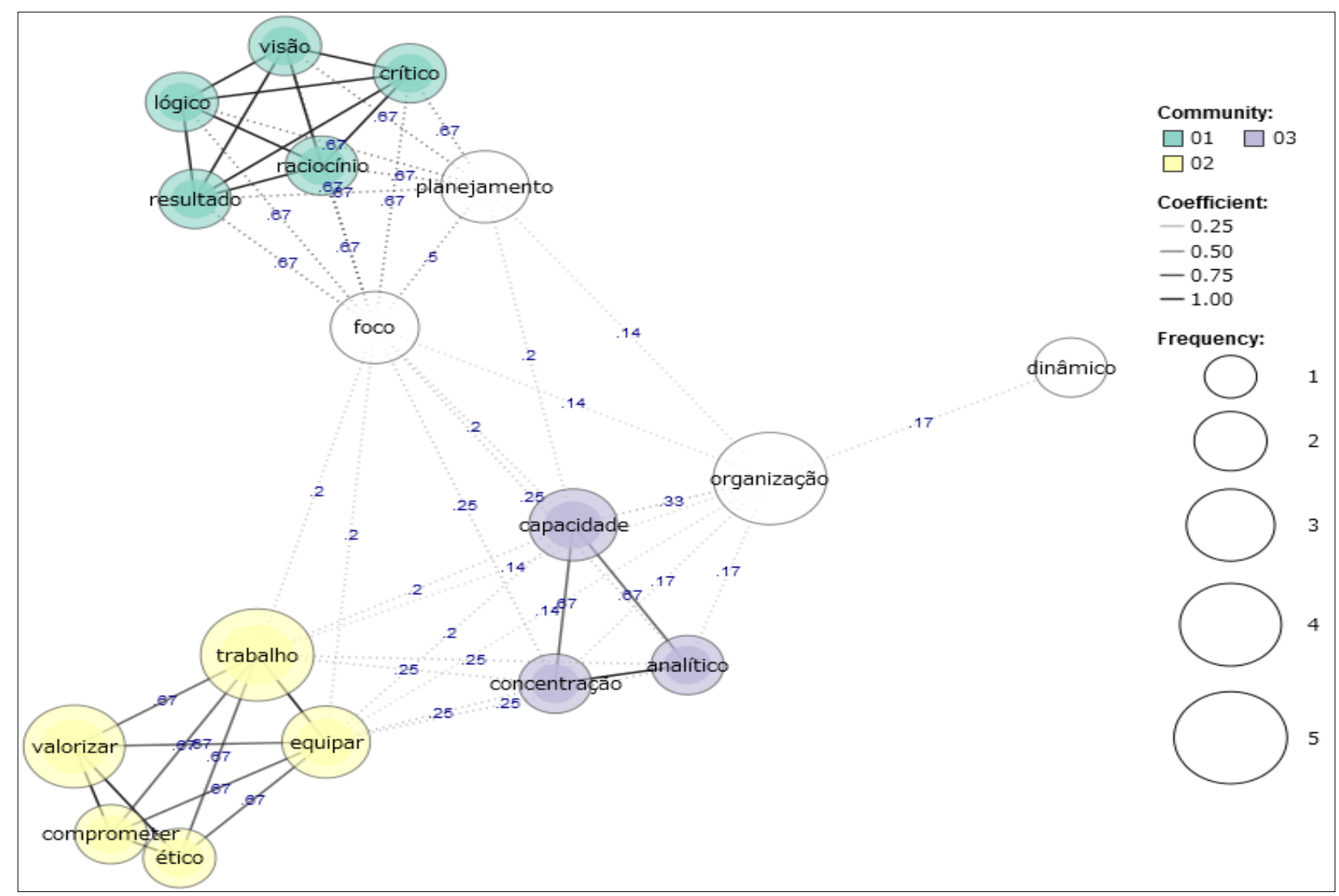

Figura 1. Rede de coocorrência de professional skills

Fonte: Elaborada pelos autores.

Na Figura 3 houve a formação de três comunidades. A comunidade 1 engloba habilidades de raciocínio lógico e visão crítica, com ênfase nos resultados. A comunidade 2 mostra a importância do comprometimento, da ética e da valorização do trabalho em equipe. Por fim, a comunidade 3 aponta para a capacidade de concentração $(J=0,67)$ e pensamento analítico $(J=$ $0,67)$, características essenciais para as funções desenvolvidas pelo profissional da área de custos. Além disso, destacam-se as habilidades de planejamento, foco, organização e dinâmica que, apesar de não estarem agrupadas em nenhuma comunidade específica, apresentaram associação exógena com as comunidades formadas.

As technical competencies do perfil profissional requerido pelo mercado de trabalho para profissionais contábeis da área de custos mostram-se multidisciplinares, abrangendo conhecimentos englobados no escopo da formação contábil, até o domínio de outros idiomas e a experiência com ferramentas tecnológicas específicas. Esse perfil está alinhado ao identificado por Anzilago et al. (2016) e Heang et al. (2019). O domínio de diferentes competências técnicas indica que o mercado de trabalho busca profissionais com capacidade de agregar valor à organização, mais maduros e preparados para iniciar as atividades. Essa postura mostra-se estratégica pois, mesmo que a faixa salarial desses profissionais seja mais elevada, há economia com treinamentos e pode haver diminuição no percentual de empregados que não se adaptam às funções desempenhadas.

A Tabela 3 apresenta uma síntese das áreas de technical competencies definidas pela IFAC em relação com as comunidades da rede de coocorrência das funções desempenhadas pelo profissional de custos identificadas nesta pesquisa (Figura 2). 
Tabela 3

Áreas de atuação (IES 2), competências técnicas e funções desempenhadas pelo profissional contábil da área de custos identificadas na rede de coocorrência

\begin{tabular}{|c|c|c|}
\hline IES 2 - Technical competencies & Coocorrência & $\begin{array}{l}\text { Competências técnicas e } \\
\text { funções desempenhadas }\end{array}$ \\
\hline Contabilidade financeira e relatórios & Comunidades 4 e 8 & \multirow{11}{*}{$\begin{array}{l}\text { Controle, } \\
\text { elaboração de relatórios, } \\
\text { conciliação, apurar e conferir } \\
\text { aspectos tributários, garantir } \\
\text { informação, analisar e elaborar } \\
\text { relatórios de custos, realizar } \\
\text { fechamentos mensais, } \\
\text { desenvolver relatórios de } \\
\text { rentabilidade, realizar estudos } \\
\text { orçamentários, acompanhar as } \\
\text { alterações de valores e propor } \\
\text { melhorias gerenciais. }\end{array}$} \\
\hline Contabilidade gerencial & Comunidades $1,3,5,6,7,8$ e 10 & \\
\hline Finanças e gestão financeira & Comunidades $4,5,6,8$ e 9 & \\
\hline Tributação & Comunidade 2 & \\
\hline Auditoria e garantia & & \\
\hline $\begin{array}{l}\text { Governança, gerenciamento de riscos e } \\
\text { controle interno }\end{array}$ & Comunidades 7,10 e 11 & \\
\hline Direito e legislação comercial & & \\
\hline Tecnologia da informação & Comunidade 2 & \\
\hline Ambiente empresarial e organizacional & & \\
\hline Economia & & \\
\hline Estratégia de negócios e gestão & & \\
\hline
\end{tabular}

Fonte: Elaborada pelos autores.

A multidisciplinaridade identificada na rede de coocorrência das technical competencies mostra concordância das demandas do mercado de trabalho com a IES 2 da IFAC. A relevância de formar profissionais de custos que dominam conhecimentos de outras disciplinas, como tributos, administração financeira, contabilidade societária, entre outros, mostra que o ambiente empresarial anseia por contadores que tenham visão crítica e sistêmica da organização como um todo, sendo focados em propor melhorias, aprimorar os controles e fomentar a rentabilidade da organização.

A rede de coocorrência das professional skills (Figura 3) destaca justamente a visão sistêmica, crítica e analítica ensejada pelo mercado de trabalho. A capacidade de trabalhar em equipe e de concentração também estão no escopo da IES 3. Esses achados são similares aos de Maelah et al. (2012), que destacou que a gestão do tempo, a comunicação oral e a capacidade de trabalhar em equipe estão entre as habilidades desenvolvidas pelos acadêmicos quando entram em contato com o mercado de trabalho.

Tan e Laswad (2018) obtiveram evidências que suportam o perfil delineado nesta pesquisa. As habilidades de relacionamentos interpessoais, visão sistêmica, raciocínio analítico, liderança e capacidade de comunicação para profissionais contábeis são valorizadas em outras partes do mundo, sendo importante o desenvolvimento dessas habilidades durante a formação acadêmica.

A Tabela 4 mostra as áreas das professional skills da IES 3 em relação com as comunidades da rede de coocorrência das habilidades profissionais verificadas nos anúncios analisados (Figura $3)$. 
Tabela 4

\section{Áreas das professional skills (IES 3) e habilidades profissionais identificadas na rede de coocorrência}

\begin{tabular}{|c|c|c|}
\hline IES 3 - Professional skills & Coocorrência & Habilidades profissionais \\
\hline Intelectual & Comunidades 1,2 e 3 & \multirow{4}{*}{$\begin{array}{l}\text { Visão e raciocínio lógico e crítico, } \\
\text { foco nos resultados e no } \\
\text { planejamento, ser dinâmico, ser } \\
\text { organizado, capacidade analítica, } \\
\text { concentração, trabalho em equipe, } \\
\text { comprometimento e ser ético. }\end{array}$} \\
\hline Interpessoal e comunicação & Comunidade 2 & \\
\hline Pessoal & Comunidades 2 e 3 & \\
\hline Organizacional & Comunidades 1,2 e 3 & \\
\hline
\end{tabular}

Fonte: Elaborada pelos autores.

Nota-se alinhamento entre as áreas das professional skills apresentadas pela IFAC e as habilidades profissionais requeridas pelo mercado de trabalho. As professional skills englobam uma pluralidade de habilidades, que podem ser desenvolvidas durante o processo de formação do profissional contábil atuante na área de custos com intuito de atender às demandas do mercado de trabalho. Cabe ao discente e às instituições formadoras desses profissionais desenvolver meios e metodologias que possibilitem o alcance dessas habilidades.

Assim, é possível identificar que o perfil profissional requerido pelo mercado de trabalho para profissionais contábeis da área de custos está pautado em possuir experiências anteriores, elaborar programas para redução de perdas, acompanhar custos fixos e variáveis, elaborar planilhas, participar do fechamento contábil, e examinar o impacto dos tributos nos custos, na formação do preço de venda e no orçamento dos fornecedores, o que mostra a importância desse profissional possuir conhecimentos multidisciplinares. O domínio de ferramentas de tecnologia da informação e da língua inglesa também são diferenciais a serem observados. Essas competências são maximizadas por um conjunto de soft skills que abrange capacidade de trabalhar em equipe, raciocínio lógico e analítico, capacidade de concentração, foco, dinamismo, organização, entre outras habilidades.

Nesse sentido, os resultados mostram-se alinhados às discussões inerentes a temática que foram desenvolvidas ao longo de diferentes épocas, tais como: Crossman (1953) que detalhou a importância do profissional contábil da área de custos para o planejamento, a supervisão e o desempenho das organizações por meio do fornecimento de dados úteis, que suportam as decisões da gerência; Loft (1986) que trouxe um olhar crítico às funções do profissional da área de custos, que está envolto pela disputa de poder dentro das organizações; ou até mesmo Johnson e Johnson (1995) que mostraram o aumento da valorização de habilidades sociais pelo mercado de trabalho ao longo dos anos, com destaque para as de comunicação, interpessoais e organizacionais.

Todas essas evidências alinham-se às recomendações da IFAC quanto ao desenvolvimento de technical competencies e professional skills durante a formação do profissional contábil. Assim, percebe-se harmonia entre as recomendações da IFAC e o anseio do mercado de trabalho. Logo, é importante que haja o direcionamento da atenção das instituições de ensino, bem como dos órgãos responsáveis pelas políticas inerentes a formação dos profissionais contábeis, para elementos que conduzam ao alinhamento do currículo pedagógico com as habilidades e competências requeridas pela IFAC, e consequentemente, com o mercado profissional.

\section{CONSIDERAÇÕES FINAIS}

A pesquisa contribuiu com diferentes discussões existentes na literatura, sendo que as evidências encontradas permitiram enriquecer os achados acerca da temática, delinear o perfil do profissional contábil atuante na área de custos desejado pelo mercado de trabalho, e responder à questão de pesquisa indicando que o perfil profissional desejado pelo mercado de trabalho para profissionais contábeis da área de custos engloba tanto competências técnicas como habilidades profissionais, conforme preconizado pela IFAC. 
Assim nota-se alinhamento entre o mercado de trabalho e as diretrizes da IFAC. Esses achados apresentam-se como uma contribuição teórica da pesquisa, ao indicar que as diretrizes da IFAC se mostram como uma lente adequada para analisar as habilidades e competências requeridas pelo mercado de trabalho e desenvolvidas nos cursos de Ciências Contábeis. Nesse sentido, o estudo contribui em termos educacionais com a área Contábil ao indicar que é preciso chamar a atenção do CFC para que essas competências e habilidades sejam englobadas nos PPCs dos cursos de Ciências Contábeis. Essa necessidade também é reforçada pelo fato de o CFC ser membro da IFAC, pois "os órgãos membros da IFAC têm a responsabilidade de garantir que a proposta de Desenvolvimento Profissional Inicial atenda aos requisitos das IES" (IFAC, 2014b, p. 3).

Ainda em termos práticos, cabe direcionar atenção aos educadores para que, no decorrer da formação dos acadêmicos em Contabilidade, sejam trabalhadas tanto as technical competencies quanto as professional skills. Assim, os estudantes terão mais oportunidades de tornar seus currículos atrativos para as organizações e de superar as barreiras por vezes existentes devido à pouca experiência profissional no mercado de trabalho. Fornecer tais direcionamentos explícitos aos acadêmicos de Contabilidade consubstancia algumas das contribuições práticas da pesquisa, pois, ao destacar as demandas do mercado de trabalho, incentiva-se os discentes a desenvolver tais habilidades e competências a fim de maximizar suas chances de empregabilidade.

A pesquisa ainda contribui no campo metodológico ao utilizar redes de coocorrência que permitiram identificar similaridades entre as descrições de anúncios de vagas de emprego e representar graficamente o perfil dos profissionais contábeis da área de custos. As limitações do estudo residem no fato de ser uma pesquisa com aspecto transversal, concentrada na análise de uma única unidade federativa do país, e restrita à atuação do profissional contábil na área de custos. Sugere-se que estudos futuros analisem anúncios de emprego de outras localidades e sites, e que a análise possa ser direcionada para outras áreas da Contabilidade, permitindo identificar as especificações de cada dimensão de atuação dos profissionais contábeis. Acredita-se que pesquisas desenvolvidas em outros campos de atuação, vinculando-os com as diretrizes da IFAC, possam contribuir com evidências que sustentam ou refutam o alinhamento dessas diretrizes com o anseio do mercado de trabalho.

\section{REFERÊNCIAS}

Anzilago, M., Bernd, D. C., \& Voese, S. B. (2016). Mercado de Trabalho dos Profissionais de Custos no Paraná: Um Estudo sobre a Demanda, Habilidades e Competências Exigidas. Contextus-Revista Contemporânea de Economia e Gestão, 14(1), 193-217.

Confederação Nacional das Indústrias [CNI] (2017). Ranking dos estados brasileiros. Recuperado em 22 abril, 2019, de http://perfildaindustria.portaldaindustria.com.br/ranking

Crossman, P. (1953). The function of the Cost Accountant in cost control. The Accounting Review, 28(1), 25-31.

Exame. (2016). 7 cargos em alta e com salários de até R\$ 7,5 mil. Revista Exame, São Paulo. Recuperado em 22 abril, 2019, de https://exame.abril.com.br/carreira/7-cargos-em-alta-e-comsalarios-de-ate-r-7-5-mil/

Forbes (2016). The Most In-Demand Jobs (And What They Pay). Forbes, New York City, 06 fev. 2016. Recuperado em 22 abril, 2019, de https://www.forbes.com/sites/karstenstrauss/2016/02/06/the-most-in-demand-jobs-and-whatthey-pay/\#55b799c1e52b 
G1 (2013). Pesquisa lista os 7 profissionais mais desejados pelas empresas. G1, São Paulo, 03 out. 2013. Recuperado em 22 abril, 2019, de http://g1.globo.com/concursos-eemprego/noticia/2013/10/pesquisa-lista-os-7-profissionais-mais-desejados-pelasempresas.html

Guia da Carreira. Os melhores sites de emprego. Recuperado em 22 abril, 2019, de https://www.guiadacarreira.com.br/carreira/emprego/os-melhores-sites-de-emprego/

Heang, L. T., Mee, L. Y., Ramalingam, L., \& Hoe, C. S. (2019). Job Opportunities and Employability Skills Required of Business Graduates in Malaysia: An Investigation through Online Job Advertisements. Journal of Marketing Advances and Practices, 1(1), 37-49.

Herawati, S. D. (2012). Review of the Learning Method in the Accountancy Profession Education (APE) Programs and Connection to the Students Soft Skills Development. Procedia-Social and Behavioral Sciences, 57, 155-162.

Higuchi, K. (2017). KH Coder 3 Reference Manual. Quioto.

Holtz, L., Cabral, I., \& Carvalho, M. da S. (2019) Análise Comparativa das Competências e Habilidade Estabelecidas nas International Education Standards e Projetos Pedagógicos de Cursos à Luz da Teoria Institucional. Anais do Congresso ANPCONT, São Paulo, SP, Brasil, 8.

Instituto Brasileiro de Geografia e Estatística [IBGE] (2016). Estatísticas. Recuperado em 22 abril, 2019, de https://www.ibge.gov.br/estatisticas/todos-os-produtos-estatisticas.html

International Federation of Accountants [IFAC] (2014a). International Accounting Education Standards Board International [IAESB]. International Education Standard (IES) 2 - Initial Professional Development - Technical Competence (revised). Recuperado em 22 abril, 2019, de https://www.iaesb.org/

International Federation of Accountants [IFAC] (2014b). International Accounting Education Standards Board [IAESB]. International Education Standard (IES) 3 - Initial Professional Development - Professional Skills (revised). Recuperado em 22 abril, 2019, de https://www.iaesb.org/

International Accounting Education Standards Board [IFAC] (2014c). International Education Standard (IES) 4 - Initial Professional Development - Values, Ethics, and Attitudes (revised). Recuperado em 22 abril, 2019, de https://www.iaesb.org/

Johnson, L. M., \& Johnson, V. E. (1995). Help Wanted-Accountant: What the Classifieds Say about Employers' Expectations. Journal of Education for Business, 70(3), 130-134.

Lemes, D. F., \& Miranda, G. (2014). Habilidades Profissionais do Contador Preconizadas pela IFAC: um estudo com profissionais da região do Triângulo Mineiro. Advances in Scientific and Applied Accounting, 7(2), 293-316.

Loft, A. (1986). Towards a critical understanding of accounting: The case of cost accounting in the U.K., 1914-1925.Accounting, Organizations and Society, 11(2), 137-169. 
Maelah, R., Aman, A., Mohamed, Z. M., \& Ramli, R. (2012). Enhancing soft skills of accounting undergraduates through industrial training. Procedia-Social and Behavioral Sciences, 59, 541549.

Michel Page. Guia de Salário 2019. Recuperado em 22 abril, 2019, de https://www.pagepersonnel.com.br/

Preobragenskaya, G. G., \& Komarev, I. (2018). Designing Market-Oriented Accounting Curriculum: A method and an Application with GCC Data. SSRN Electronic Journal. doi: $10.2139 /$ ssrn.3292924

Reis, A. O., Sediyama, G. A. S., de Souza Moreira, V., \& Moreira, C. C. (2015). Perfil do profissional contábil: habilidades, competências e imagem simbólica. Revista Contemporânea de Contabilidade, 12(25), 95-116.

Souza, M. A., \& Gomes, T. V. S. (2013). Um perfil de contadores de custos: estudo com profissionais de empresas do polo industrial de São Leopoldo, RS. ABCustos, 8(2).

Tan, L. M., \& Laswad, F. (2018). Professional skills required of accountants: what do job advertisements tell us? Accounting Education, 27(4), 403-432. 